Article

\title{
From Textile Waste to Resource: A Methodological Approach of Research and Experimentation
}

\author{
Silvia Tedesco * and Elena Montacchini \\ Department of Architecture and Design, Politecnico di Torino, 10125 Torino, Italy; elena.montacchini@polito.it \\ * Correspondence: silvia.tedesco@polito.it
}

Received: 30 November 2020; Accepted: 15 December 2020; Published: 21 December 2020

check for updates

\begin{abstract}
The transition to a circular economy shifts the focus onto reusing, renewing and recycling existing materials and products, considering waste as a resource. In this context, this article aims to describe the life cycle approach's potential for the development of new building products from textile waste, one of the most environmentally impacting activities at a global level, both in relation to the processes that characterise the supply chain and in relation to pre- and post-consumption waste. This article outlines the research methodology adopted by the cluster "From textile waste to resource" of the Department of Architecture and Design, Politecnico di Torino, through the description of research projects carried out in partnership with Small and Medium Enterprises (SMEs). In particular, it highlights the methodological approach adopted in a "grave to cradle" logic, in which the waste from one process becomes a new resource for another. This article highlights some open issues related to the limits and potential of the use of the life cycle approach as a "tool" to compare different options in a preliminary experimental research phase, to verify the environmental impacts of new materials and products made from recycled materials, and to compare new options with similar solutions available on the market.
\end{abstract}

Keywords: circular economy; life cycle approach; from waste to resource; building materials and products

\section{Introduction}

The transition to a circular economy represents one of the key actions of the European Union [1], which considers it a priority to invest in a linear model as an alternative to the current one, linked to "production-consumption-disposal". The transition to a circular economy shifts the focus onto reusing, renewing and recycling existing materials and products, considering waste as a resource [2].

Supported by international policies, the circular economy can be a driver of innovation and an opportunity for numerous sectors, including construction. The data reported in the document published by the Italian Ministry of the Environment under the title "Towards a circular economy model for Italy" highlight the strategic importance of the construction industry in the development of an economy in which the sustainable use of resources and the use of waste become the keys to a new development model [3]. In this sense, Italy has introduced Minimum Environmental Criteria (CAM), public policy tools capable of promoting the use of products with recycled content and materials with a low environmental impact throughout their life cycle [4].

Legislative support and incentives for the development and use of products obtained from the recycling of secondary raw materials are leading to the dissemination of cooperative projects and good practices between companies, research organisations and start-ups specialising in the reuse and recycling of waste and secondary raw materials $[5,6]$. 
Waste, sometimes from sectors apparently distant from the building industry, can represent a strategic opportunity for the development not only of new products but also of new "circular" supply chains and processes of industrial symbiosis.

\section{Background}

The textile industry is the third most important manufacturing sector in Italy in economic terms. The fashion industry is considered to be a benchmark of excellence in Italy and Italian fashion revenues are remarkable [7]. However, at the same time, the textile system is one of the most environmentally impacting activities at a global level, both in relation to the processes that characterise the supply chain and in relation to pre- and post-consumption waste [8].

According to the SMI (Sistema Moda Italia) Textile and Fashion Federation, the textile sector produces 3.4 million tonnes of global greenhouse gas emissions annually, consumes 6-9 billion litres of water and uses 6 million tonnes of chemicals [9].

In relation to the waste produced, in the pre-consumption phase, $37.4 \%$ of non-hazardous manufacturing waste comes from textiles, clothing and the tanning industry [10]; according to the Boston Consulting Group Pulse of the fashion industry report (2017), by 2030 the sector's waste production will have risen by $63 \%$, and this increase in waste will be accompanied by an increase in $\mathrm{CO}_{2}$ emissions [11].

Tonnes of waste end up in landfills every year-waste that could be returned to a new production cycle with a view to circular economy and industrial symbiosis.

The textile sector is one of the key product value chains of the new circular economy action plan, which focuses on the sectors that use the most resources and where the potential for circularity is high. The key actions promoted include: "boosting the sorting, re-use and recycling of textiles, including through innovation, encouraging industrial applications and regulatory measures such as extended producer responsibility" [1].

Several international studies have applied the Life Cycle Assessment (LCA) methodology to the textile sector, highlighting environmental impacts and indicating strategies for their reduction. Within the scope of the strategies proposed, research has shown that great environmental savings can be achieved if solutions for recycling and reusing used clothing are adopted in the post-consumption phase, as this can prevent or minimise the production of new garments [12].

In this context, the concept of upcycling, meaning the process of transforming textile waste into resources for new products with greater economic and environmental value, is of particular interest. Textile waste has huge potential for reuse, as demonstrated by research and applications in many sectors, including the automotive and eco-design industries [13]. Recent applications have highlighted the potential for reuse in the construction sector, such as in the thermal and acoustic insulation of buildings [14].

The life cycle approach is still one of the main methodologies for product assessment and process planning, useful for the development of circular economy solutions and strategies. LCA is configured as a tool to compare different options in a preliminary experimental research phase, to verify the environmental impacts of new materials and products made from recycled materials and to compare new options with similar solutions available on the market. Moreover, the LCA method is a holistic approach that supports the assessment of environmental performance in the context of industrial symbiosis because it includes the entire supply chain: from the selection of solutions with the lowest environmental impact to the assessment of the industrial symbiosis pathways, with the aim of understanding the effective improvement of the environmental performance of the whole system.

Based on these considerations, this article aims to illustrate the potential of the life cycle approach for the development of new building products using textile waste. 


\section{Materials and Methods}

\subsection{The Activities of the "From Textile Waste to Resource" Cluster}

"From textile waste to resource" is a cluster created by the TeAM (Tecnologia e AmbienteTechnology and Environment) group of the Department of Architecture and Design of Politecnico di Torino.

The aim of the cluster is to provide enterprises with proper skills in order to support technological innovation and the implementation of a recycling supply chain. The cluster also aims to test the opportunity to use such waste as secondary raw material for manufacturing environmentally friendly products to be used in the building and eco-design sectors. In recent years, it has taken part in a variety of experiences, including Ediltex, a research and training project which involved companies belonging to a territorial district in Tuscany historically dedicated to textile manufacturing, with the aim of identifying possible scenarios for the recycling of production waste [15]; TECA Panel (Textile Experimental Composite Acoustic), a project aimed at developing sound-absorbent panels for interior use, using textile waste [16]; and Not Too Bed, an experimental study on the post-consumption reuse of mattresses in combination with phase-changing materials for filling car seats [17].

Through the description of some projects carried out by the cluster in collaboration with Small and Medium Enterprises, the contribution highlights the methodological approach adopted, in a "grave to cradle" logic, in which waste from one process becomes a new resource for another, highlighting the limits and potential of the use of LCA as a tool for assessing the environmental impacts of new products.

\subsection{The Methodological Approach of the Cluster to Research and Experimentation}

The methodological approach used by the research group for the development of new products and circular scenarios is characterised by upcycling concepts and is based on the following macro-phases:

- Development of environmental audits within companies, to identify types and quantities of production waste;

- Study of data from international scientific literature and databases, aimed at identifying potential recycling applications for the manufacture of building products;

- Mix design, experimentation and prototyping;

- Verification of the results from the point of view of technological and environmental performance;

- Identification of the actors and stakeholders of the supply chain (public and private) and proposals for new circular economy scenarios.

\subsubsection{Environmental Audits}

The environmental audit phase within the companies allows the study and knowledge of the production system, the identification of the processes that have the greatest impact and the assessment of the improvement actions that can be implemented.

For the initial acquisition of data, the TeAM group has developed a questionnaire as a tool for approaching and getting to know the companies involved in the projects, with the aim of characterising: the quantities of products, by-products and waste; production processes; machinery and equipment; methods of treatment and/or disposal of by-products and waste.

The questionnaire is divided into three macro topics, including a first part dedicated mainly to company data, followed by a second section dedicated to the type of industrial production and production volumes. The final part focuses on the production of waste, defining the type, quantity, production frequency and cost of disposal. The study of the production and waste management process, the definition of the input-output system of the production process and the outlining of the corresponding flow chart are carried out through inspections and interviews within the company. A graphic representation (Flow Chart) makes it easier to understand the production chain, by-products and waste. 


\subsubsection{Study of Data from Scientific Literature and Databases}

To assess the potential reuse and recycling of waste materials and identify potential applications for the manufacture of building products, state of the art analyses are carried out using the main international scientific research platforms, such as Scopus, ResearchGate and Science-Direct. Once a research time frame has been defined and the main keywords have been selected, the scientific documentation extracted is catalogued in a database, subdivided by subject and type of article (review, experimental or argumentative); articles that document information considered relevant for the following phases of experimentation are then filed.

Further research is carried out in virtual material libraries dedicated to sustainable, recycled and recyclable materials, such as MATerial RECycling (www.matrec.com), Material Connexion (www.materialconnexion.com), and MATto (www.matto.design/it/home-page), along with a prior analysis of patents and utility models, using Orbit (www.orbit.com). This set of data is the basis for the mix design, experimentation and prototyping phases, as it gives us an understanding of the techniques, processes and potential of any previous experiences.

\subsubsection{Mix design, Experimentation and Prototyping}

The mix design and experimentation activities include an initial phase in which the materials are selected and characterised physically and chemically and of preliminary feasibility studies, functional to the production of specimens.

On the basis of the results obtained, prototypes are then created on which to test performance and assess the eco-compatibility of the production processes.

The research group is supported by the Politecnico di Torino Laboratories and particularly by the Innovative Technological Systems Laboratory (LaSTIn). The Laboratory is equipped to carry out tests on materials, components and systems, connected to both advanced research projects and performance certification activities in the energy and environmental fields (Figure 1).
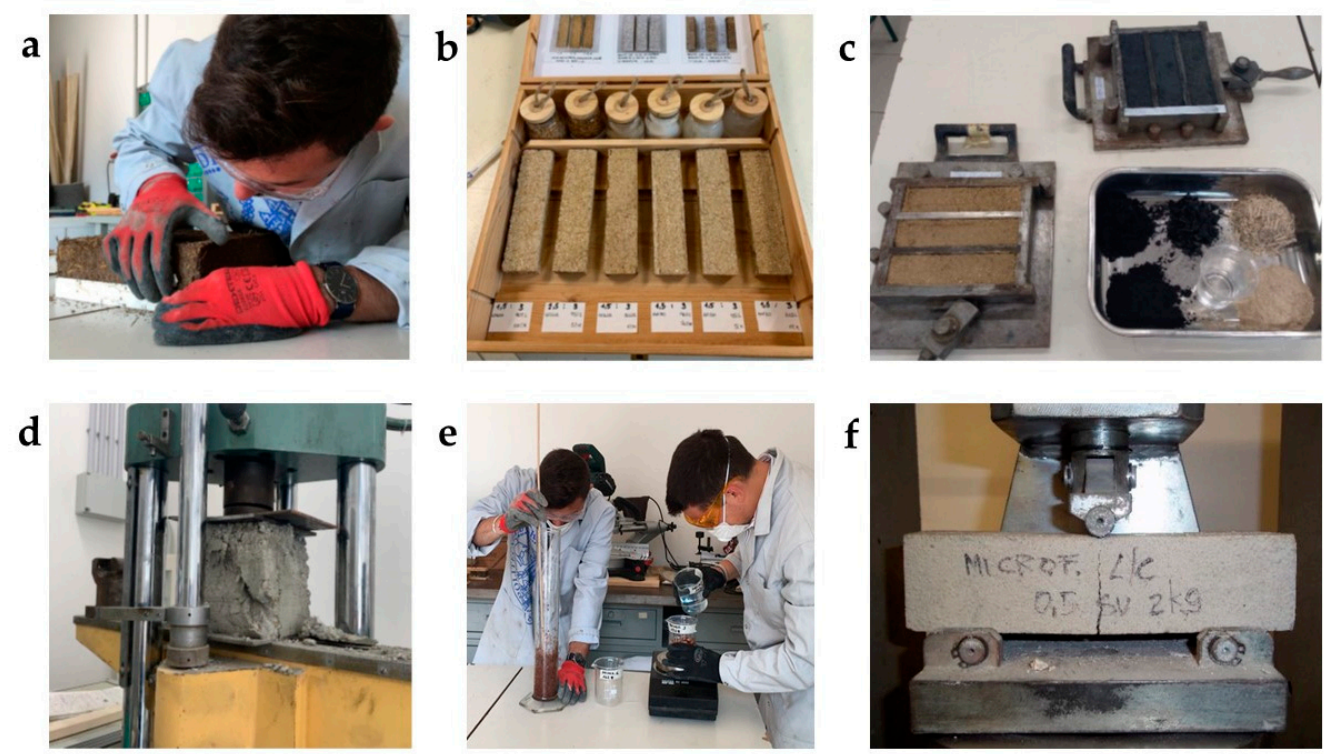

Figure 1. Experimental activities at the LaSTIn laboratory (Politecnico di Torino) on different materials, for example: (a) manufacture of a concrete and hazelnut shell specimen; (b) manufacture of specimens using rice husks and natural adhesives; (c) shaping of specimens using hemp and biochar; (d) compression test of a concrete and natural fibre specimen; (e) weighing and mixing of agri-food waste; (f) flexure test of a plaster specimen using textile waste. 


\subsubsection{Technological and Environmental Assessments}

The specimens and/or prototypes produced are checked for mechanical resistance and thermal and acoustic performance in accordance with the applicable technical standards, based on the specific aim of the project.

Life Cycle Assessments (LCA) are carried out to assess environmental impacts, based on ISO 14040:2006 [18] and ISO 14044:2018 [19]. The analyses are carried out using specific software tools (e.g., Sima Pro, eTOOL, Open LCA) with direct data (provided by companies and/or collected through audits) and data gathered from previous studies (previous LCA, Environmental Product Declaration studies) and databases (Ecoinvent, ELCD). The use of the LCA methodology is an effective way to develop products and technical elements, from design to production and monitoring activities, through to the end of life. The following impact indicators are assessed: Embodied Energy (EE), i.e., the amount of energy used throughout the product's entire life cycle, from production to disposal $(\mathrm{MJ} / \mathrm{kg})$; and Embodied Carbon (EC), i.e., the carbon footprint of a material, which considers how many greenhouse gases, expressed in carbon dioxide equivalent $\left(\mathrm{kgCO}_{2} / \mathrm{kg}\right)$, are released throughout its life cycle.

\subsubsection{Supply Chain Scenarios}

The last phase involves the design of specific circular supply chain scenarios for the companies involved. In general, the network stakeholders and the phases of the new process are identified. More specifically, the equipment needed to carry out waste collection and any packaging operations, the places used to store the material, the industrial processes for the transformation of the material and a forecast of costs and revenues for the creation of the circular scenario are identified.

\subsection{Research and Experimentation Experiences}

Two studies recently carried out by the TeAM group in accordance with the methodological approach illustrated in Section 3.2 are described below: the first, MAST (Mattone in Argilla con Scarti Tessili-Clay Brick from Textile Waste), is aimed at the integration of polyester fibres into clay bricks; the second, ReCash Plaster (Recycled Cashmere for Plaster), is aimed at the recycling of wool and cashmere fibres inside the plaster mixture. The studies were developed by the research group in collaboration with companies in the textile and construction sectors [20].

\subsubsection{MAST}

MAST (Mattone in Argilla con Scarti Tessili-Clay Brick from Textile Waste) is a pre-feasibility study aimed at exploiting pre-consumption textile waste within the brick production chain. The study was carried out taking as reference the territory of the Poirino Altopiano (Turin, Italy), the history of which is economically influenced by two industrial resources, fabric and clay. The fabric industrial resource is mainly linked to the city of Chieri, where fabric processing has its origins in the 13th century; even today there are still several established industries that produce excellent quality fabric, not only in Chieri, but also in neighbouring cities, such as Poirino. The clay industrial resource is mainly linked to the city of Cambiano, where historical references confirm the existence of a clay quarry already in the 18 th century that was used to make tiles and bricks.

The textile company involved in the experimentation is FIDIVI Tessitura Vergnano of Poirino, which specialised in the production of single-material polyester technical fabric; the furnace is Fornace Carena of Cambiano, dating back to 1907. The present quarry is exactly the one that was opened by the founders of the furnace, which takes four different types of red clay, differing in grain size. The furnace is specialised in bricks for walls, for floors and internal partitioning.

During the audit phase, a sampling of textile waste such as selvedges, post-spinning waste, end-of-roll waste and panel cuttings, which differ in terms of the type of waste but all consist of a prevalence of polyester fibres, supplied by FIDIVI Tessitura Vergnano, was carried out. Post-spinning 
waste was chosen because, besides being entirely mono-material, it requires limited shredding operations and is better suited to incorporation into the clay mixture.

Scientific studies have made it possible to understand the state of the art and the development potential with regard to clay bricks. Some interesting experiments involving the use of textile waste inside clay bricks show that the incorporation of polyester waste fibres reduces the number of cracks that form during drying due to internal tensions [21], and that the use of shredded fabrics incorporated into the processing of a solid clay brick improves resistance to compression [22].

On the basis of this information, the experimental phase was aimed at verifying the mechanical and physical-technical performance of various mixtures of clay and textile waste.

The polyester threads were shredded into sizes between $2 \mathrm{~mm}$ and $7 \mathrm{~mm}$. This process was carried out by hand. The shredded waste was used to make five mixtures with clay in the following waste to total concentrations: $0 \%, 1.5 \%, 3 \%, 4.5 \%$ and $6 \%$. Eight specimens were mixed for each blend; each mixture with the five different percentages was mixed by a kneading machine that rotates the clay mixture to make it malleable. The specimens, which measured $120 \times 60 \times 30 \mathrm{~mm}$, were dried and then traditionally fired at the Fornace Carena (Figure 2).
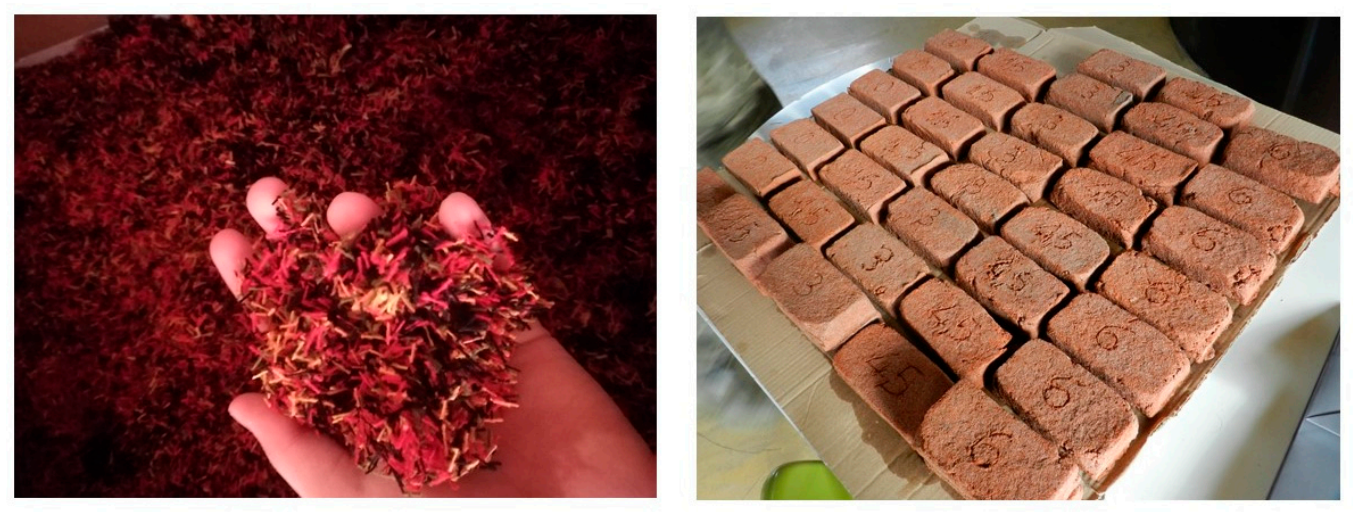

Figure 2. MAST (Mattone in Argilla con Scarti Tessili-Clay Brick from Textile Waste): from textile waste to experimental specimens. On the left, shredded polyester threads; on the right, clay bricks obtained with different percentages of polyester waste.

In the drying phase, the bricks are passed through a 70m long tunnel, in which the temperature is controlled in the different chambers at $60^{\circ} \mathrm{C}$. In this way, the water stored inside the clay is evaporated, drying the brick. After about $36 \mathrm{~h}$ the bricks leave the drying kiln and are moved to enter the firing kiln in a tunnel where $1050^{\circ} \mathrm{C}$ is reached. The firing must be uniform and homogeneous; it is at this stage that the shredded polyester strands are probably completely burnt out, leaving empty pores, which could lead to a thermal improvement.

This was followed by testing for resistance to compression and the measurement of the density, giving the thermal conductivity value. The resistance to compression test and density measurements were carried out at Fornace Carena, who offered to use their quality control laboratory equipment. The thermal conductivity value was obtained from the UNI EN 1745 standard methods for determining thermal properties, through linear interpolation. The best results from the mechanical and thermal point of view were obtained with the mixture between $1.5 \%$ and $3 \%$, as the polyester waste, which burns during firing, leaves pores that improve the thermal conductivity value without compromising mechanical performance.

Moreover, the relevance of the experimentation carried out with the Criteri Ambientali Minimi (CAM) for brick building components was positively assessed: the use of a certain percentage of textile waste in the processing of bricks complies with requirements, although this waste is no longer present in the finished product after firing.

In addition, a comparative LCA made it possible to assess the environmental performance of the new clay mixture compared to benchmark products available on the market. 
At the end of the MAST research, it was possible to formulate three development scenarios for the industrial supply chain, each with its own strengths and weaknesses. In these cases, it is necessary to address one of the main nodes in the territory of the Poirino Altopiano: the way and location in which the waste can be shredded. In the first scenario, it is the textile company itself that takes care of the shredding of waste and its reintroduction to the market in different sectors. In the second scenario, the waste is transported and shredded at the furnace, where it is fed directly into the clay mixture. The third scenario involves the shredding of the waste by a recycling company interested in being part of the supply chain and located in the vicinity of the two companies.

\subsubsection{ReCash}

ReCash Plaster (Recycled Cashmere for Plaster) is a pre-feasibility study aimed at exploiting pre-consumption textile waste in plaster mortars. The study was carried out with the textile district of Biella as the reference point and involved a leading plaster manufacturer (Vimark srl, Peveragno, Cuneo, Italy). The district of Biella is recognized in the textile-clothing sector due to its production of wool, and it has been able to obtain a strong position at world level over the years. Even if it has known the diversification of the typical production of the industrial districts of textile-clothing over time, this type of production remains the characteristic one of this territory, thanks to particularly favourable conditions such as the presence of numerous watercourses, which are necessary for wool manufacturing.

Twenty of the textile companies in the district were mapped, the production processes were investigated and flow charts were developed to highlight the types and quantities of waste generated in the various phases.

The analysis of the companies in the area made it possible to identify three prevalent types of waste: dust and microfibres, selvedge and undercards. The most interesting were powders and microfibres, which represent a disposal cost for companies as they cannot be reprocessed (i.e., they cannot be returned to the production cycle and spun again), and they are the most suitable for the purposes of the experimentation. Scientific research documents significant experiments using textile waste in the form of powders and microfibres to improve the physical performance of mortars [23], and woollen fibres to strengthen cement [24].

Among the waste selected, the most interesting in terms of quantity, composition and size was wool and cashmere dust from Lanificio Fratelli Piacenza in Pollone (Biella, Italy). This waste takes the form of microfibres pressed into rectangular or cylindrical bales and is currently destined for landfill.

In the experimental phase, starting with a pre-mixed fibreglass plaster (based on cement and aerial lime) produced by the Vimark company, the glass fibres contained in the mixture $(0.25 \mathrm{~g} / \mathrm{Kg})$ were replaced with different concentrations of textile waste. The tests were carried out with $0.25 \mathrm{~g} / \mathrm{kg}$, $5 \mathrm{~g} / \mathrm{kg}$ and $7 \mathrm{~g} / \mathrm{kg}$ of wool and cashmere dust, respectively. The percentages of fibres used for the preparation of the mixtures were the same as those used for Vimark lightened plasters, with the aim of verifying how much the textile fibre contributes to obtaining significant results (Figure 3).

Laboratory tests were carried out on different design mixes (in accordance with UNI EN 998-1 and UNI EN 1015) to verify the contribution of the textile fibre: these included tests on fresh mortar, for consistency or the percentage of water in the mix, and 28-day tests, for adhesion to the substrate, flexural and compressive strength. Comparing the final results with the fibreglass plasters currently produced in the factory, the tests carried out with $5 \mathrm{~g} / \mathrm{kg}$ of textile waste showed a significant improvement in performance because adhesion to the substrate doubled and mechanical resistance to both bending and compression was considerably higher.

Moreover, a comparative LCA made it possible to assess the environmental performance of the new blend compared to benchmark products available on the market.

Based on the results of the research and experimentation activity, two possible supply chain scenarios were imagined for the networking of the company that produces the waste and the company that receives it. These scenarios revolve around the problem of storing, processing and transporting 
waste. The first scenario involves the plaster manufacturer, which would have to invest in a machine for the industrialised dispersion of the fibres in the mixture, which was carried out manually during the experimental phase. The second scenario involves the addition of an element to the supply chain between the company supplying the waste and the company producing the plasters: a third company capable of taking the waste and processing it for subsequent economic exploitation as a new resource. Each of these scenarios presents strengths and weaknesses that deserve to be discussed during the industrial development phase, but each scenario is formulated to foresee economic advantages for the parties involved. In an upcycling concept, some pre-consumption textile waste can be transformed from waste into a resource and included in a new "value chain" [20].
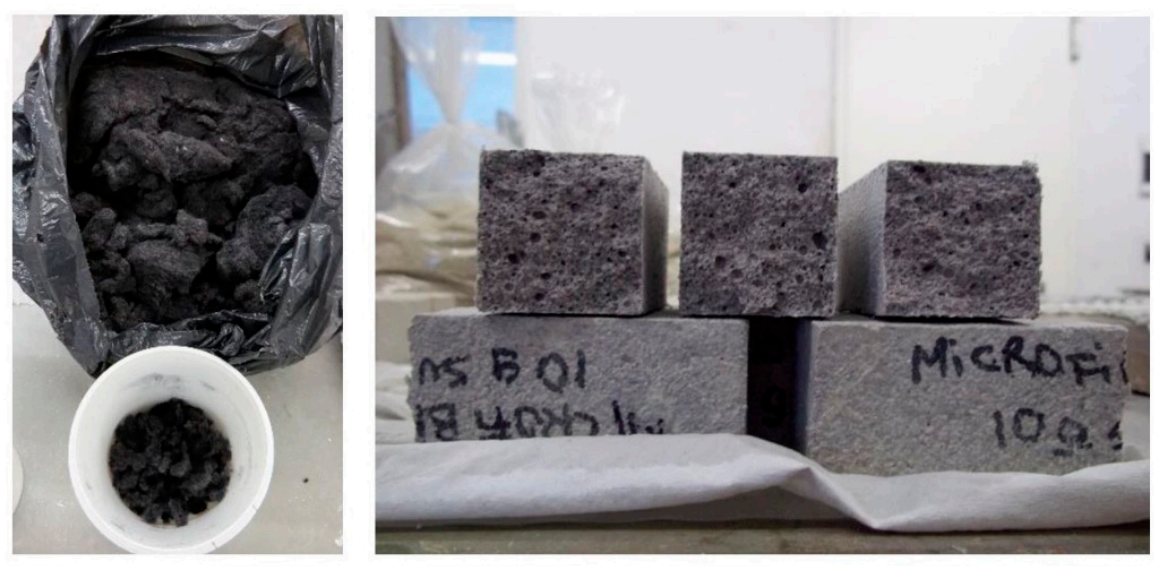

Figure 3. ReCash Plaster (Recycled Cashmere for Plaster): from textile waste to experimental specimens. On the left, wool and cashmere dust; on the right, pre-mixed plaster obtained by replacing glass fibres with textile waste.

\section{Results and Discussion}

During the monitoring of the physical and technical performance, a study of the life cycle of the two products was carried out in order to understand the potential use of textile fibres for the manufacture of eco-products for the building industry and to compare the results with benchmark products available on the market.

The study of the life cycle of the two products, using the Life Cycle Assessment method [18], was carried out on $1 \mathrm{~kg}$ of finished product in order to quantify the main input flows (raw materials and secondary raw materials, by-products, energy resources, etc.), output flows (finished product, waste and emissions) and assess the environmental impact. The LCA analysis refers to the "cradle to gate" phase, i.e., from the extraction of raw materials to the company's exit gate.

In this sense, the assessment was carried out using the Embodied Energy (EE) and Embodied Carbon (EC) parameters, as described in UNI EN 15978:2011 [25].

EE in particular, expressed in MJ, represents the amount of primary energy consumed by materials. The energy inputs were calculated for: the extraction and processing of raw materials and by-products, transport to the manufacturing company and the production processes of building materials. $\mathrm{EC}\left(\mathrm{kgCO}_{2} \mathrm{eq}\right)$ represents the carbon equivalent emitted by the extraction, transport and production processes of materials and is comparable to the Global Warming Potential (GWP).

An LCA study was carried out on the best MAST blends containing post-production polyester fibres $(1.5 \%$ and $3 \%)$. Direct and indirect data were used referring to Italy. The direct data were processed with the project partner company, while the indirect data were obtained from databases and bibliographies [26].

The EE and EC elaborations, related to the contribution from polyester textile waste, were calculated using data available in databases. However, the company from which the textile waste was taken did not provide information on the volumes of waste produced in relation to the production of the 
main product. In this sense, the mass allocation of polyester fibre impacts was elaborated using two scenarios. In the first case, the data were found in the Assosistema report [27], setting the allocation at $1.5 \%$. In the second case, however, a worst-case scenario was chosen based on worldwide data for textile waste destined for landfill $[28,29]$, setting the allocation of the impacts at $5 \%$. Lastly, the results were compared with product data obtained through: databases (ICE - Inventory of Carbon and Energy), bibliographical sources [26] and EPD product certifications (EPD Italy).

Table 1 shows the results obtained from the LCA and the comparison with the products selected according to the same construction material category.

Table 1. Results obtained from the Life Cycle Assessment (LCA) and the comparison with the products selected.

\begin{tabular}{cccccc}
\hline Parameter & $\begin{array}{c}\text { MAST 1,5 } \\
\mathbf{( 1 . 5 - 5 \% )}\end{array}$ & $\begin{array}{c}\text { MAST 3 } \\
\mathbf{( 1 . 5 - 5 \% )}\end{array}$ & $\begin{array}{c}\text { General Brick } \\
\text { ICE Database }\end{array}$ & $\begin{array}{c}\text { General Brick } \\
\text { [26] }\end{array}$ & $\begin{array}{c}\text { Stabiliza2 srl Brick } \\
\text { (EPD ITALY) }\end{array}$ \\
\hline $\mathrm{EE}(\mathrm{MJ} / \mathrm{kg})$ & $1.86-2.12$ & $1.94-2.45$ & 3 & 1.93 & 1.16 \\
$\mathrm{EC}(\mathrm{kgCO} 2 \mathrm{eq})$ & $0.13-0.14$ & $0.12-0.13$ & 0.24 & 0.14 & 0.052 \\
\hline
\end{tabular}

The comparison determined that the environmental impact of MAST prototypes is in line with the products and data found in databases. However, the results obtained highlighted a strong sensitivity to changes in the percentage of allocation of the impacts of polyester fibres. Furthermore, it will be necessary to industrialise the MAST prototypes in order to quantify the energy savings due to the combustion of polyester fibres within the brick firing processes.

At the same time, an LCA was carried out for ReCash plaster containing the highest percentage $(5 \%)$ of post-production wool and cashmere microfibres (dust). This assessment was developed using the open LCA programme and the Australian database OzLCI2019. The choice of this database was due to the need for cashmere data that are not readily available in European databases. The direct data were collected by the Italian companies selected and contacted for research based on the type of production of the textile supply chain. The companies provided information on the quantity of waste in the form of dust produced per annum compared to the annual quantity of the main product (kg/year). On average, $2000 \mathrm{~kg} /$ year of suction dust was calculated on 10,000,000 kg/year of product $(3,000,000$ linear metres of fabric). In this sense, the allocation of the impacts of cashmere and wool microfibres was set at $0.02 \%$.

Table 2 presents the results of the LCA carried out for ReCash plaster (5\%) and the comparison with the results of other plasters taken from the database (fibreglass plaster with data from the OzLCI2019 database and general plaster with data from the ICE database of the University of Bath), bibliography [26] and EPD product certifications.

Table 2. Results of the LCA carried out for ReCash plaster (5\%) and the comparison with the results of other plasters.

\begin{tabular}{cccccc}
\hline Parameter & $\begin{array}{c}\text { ReCash 5 } \\
\mathbf{( 0 . 0 2 \% )}\end{array}$ & $\begin{array}{c}\text { Plaster with } \\
\text { Glass Fibres } \\
\text { OzLCI2019 Database }\end{array}$ & $\begin{array}{c}\text { General } \\
\text { Plaster ICE } \\
\text { Database }\end{array}$ & $\begin{array}{c}\text { General Plaster } \\
\text { [26] }\end{array}$ & $\begin{array}{c}\text { Gypsum Based } \\
\text { Plaster (EPD } \\
\text { Environdec) }\end{array}$ \\
\hline $\mathrm{EE}(\mathrm{MJ} / \mathrm{kg})$ & 1.25 & 8.9 & 1.8 & $2.40-6.42$ & 3.195 \\
$\mathrm{EC}\left(\mathrm{kgCO} \mathrm{eq}_{2}\right)$ & 0.136 & 0.91 & 0.12 & $0.41-1.17$ & 0.151 \\
\hline
\end{tabular}

A comparison of the results showed that ReCash plaster has a similar, if not lesser, impact on the environment in some cases than the other plasters in the two parameters studied. This is largely due to the use of waste materials in its composition. However, in future research it will be necessary, if possible, to use an Italian or European database in order to obtain more precise results.

However, on the basis of the results obtained, it must be pointed out that the EE parameter of the two products analysed was determined on laboratory data and equipment. The transfer of processes 
from a laboratory to an industrial scale could reduce energy consumption. In fact, the policies on the strategic and sustainable use of energy adopted by the European Union [30], acknowledged by Italy through a National Plan for energy and climate [31], the strategies for the implementation of Industry 4.0 and the use of energy-efficient machinery and equipment allow us to assume a decrease in energy demand between $5 \%$ and $15 \%$ on an industrial scale [32]. In this sense, it will be necessary to extend the LCA assessment to an industrial scale in order to quantify the energy demand (EE) and the corresponding emissions (EC).

\section{Conclusions}

This contribution demonstrates how, using the Life Cycle approach as a design tool, it is possible to "design" not only new products but also new processes of circular economy. In addition to the specific results obtained in the individual studies or by their level of maturity and investigation, the methodology adopted was used transversally, at different moments in the design process (from the conception of solutions to the verification of environmental performance), with the ultimate aim of identifying ways to restore value to waste products through upcycling and imagining new perspectives of industrial symbiosis based on the principles of circular economy.

However, it is necessary to highlight some critical issues related to the LCA approach and tools to assess impacts. The LCA methodology envisages a level of articulation and complexity that requires specific expertise, the elaboration of a large amount of data and rather long implementation times, which are often incompatible with the ordinary design and production times of any construction product. Another aspect that contributes to limiting the potential for the application of the LCA methodology in the building industry is attributable to the "accessory" character that the players in the building process have assigned to it up to now, using it as a tool for environmental self-certification or, worse, for green-washing, maintaining the logic of off-site production of products according to the "end of pipe" approach (acting at the end of the cycle, downstream of the production process and treating pollution after it has been produced).

Despite currently being one of the most widely used environmental assessment methods, it should be noted that the LCA does not allow the quantification of certain strategies that characterise the circular economy in construction, such as "design for disassembling" (a design approach aimed at increasing the second life of building elements and components), which could reduce the value of Embodied Energy and Embodied Carbon to be attributed to elements and components. Therefore, the LCA methodology should be characterised in the future by circularity indicators complementary to those currently in use.

However, the research and experimentation activities carried out in collaboration with Small and Medium Enterprises (SMEs) document a growing interest in these issues, not only from the academic world but also from manufacturing. Overall, the results show that new virtuous processes can be implemented according to a systemic approach that connects sectors that are only apparently distant from each other, such as textile production and construction.

However, for the transition from a laboratory to an industrial scale, important issues related to industrial symbiosis among companies will have to be considered. It will be necessary to verify the business strategy implications of a new "sharing economy" and analyse the barriers and opportunities related to the transition from a linear model to a circular one. On the one hand, the technical feasibility will have to be analysed in terms of the material resources (e.g., equipment and spaces) and immaterial resources needed (e.g., technical skills); on the other hand, the economic viability will have to be assessed and the advantages/disadvantages for the companies defined.

The transition path towards a circular economy might not be easy for companies, such as SMEs, which have poor R\&D and financial resources, but the collaboration with universities and the possibility to access European and national funding could successfully support this process in the near future. 
Author Contributions: This paper is to be attributed in equal parts to the authors. All authors have read and agreed to the published version of the manuscript.

Funding: This research received no external funding but received material and immaterial support from the companies involved.

Acknowledgments: Acknowledgement goes to Jacopo Andreotti and Monica Alexandra Muñoz Veloza who have written Part 4 of the article and carried out the LCA analyses. We would like to thank: for MAST research, arch. Laura Giusto, FIDIVI Tessitura Vergnano and Fornace Carena; for ReCASH research, arch. Simone Fiorina, Vimark, Lanificio Fratelli Piacenza.

Conflicts of Interest: The authors declare no conflict of interest.

\section{References}

1. European Commission. Communication: A new Circular Economy Action Plan for a Cleaner and More Competitive Europe, Brussels 11 March 2020. Available online: https://ec.europa.eu/environment/circular-ec onomy/ (accessed on 24 November 2020).

2. European Commission. Communication: Closing the loop-An EU action plan for the Circular Economy, Brussels 2 December 2015. Available online: https://eur-lex.europa.eu/legal-content/EN/TXT/?uri=CELEX\% 3A52015DC0614 (accessed on 24 November 2020).

3. Ministero dell'Ambiente-Governo Italiano. Verso un Modello di Economia Circolare Per l'Italia. Documento di Inquadramento e di Posizionamento Strategico. 2017. Available online: http://consultazione-economiacirc olare.minambiente.it/sites/default/files/verso-un-nuovo-modello-di-economia-circolare_HR.pdf (accessed on 24 November 2020).

4. Ministero dell'Ambiente-Governo Italiano. Criteri Ambientali Minimi Per L'affida-Mento di Servizi di Progettazione e Lavori per la Nuova Costruzione, Ristrutturazione e Manutenzione di Edifici Pubblici, Decreto 11 Ottobre 2017. Available online: https://www.gazzettaufficiale.it/eli/id/2017/11/06/17A07439/sg (accessed on 24 November 2020).

5. Pauli, G.A. The Blue Economy Version 2.0: 200 Projects Implemented, US \$4 Billion Invested, 3 Million Jobs Created; Academic Foundation: Haryana, India, 2015.

6. Zamboni, S. L'Italia Della Green Economy. Idee, Aziende, Prodotti nei Nuovi Scenari Globali; Edizioni Ambiente: Milano, Italy, 2011.

7. Crivelli, G. Textile and Fashion Industry Generates Half of Italy's Trade Surplus, Il Sole 24 ore Digital Edition, 2017 May. Available online: http://www.italy24.ilsole24ore.com/print/AE85yCTB/0 (accessed on 24 November 2020).

8. Chowdhury, A.R. Environmental impacts of the textile industry and its assessment through life cycle assessment. In Roadmap to Sustainable Textiles and Clothing; Springer: Singapore, 2014; pp. 1-39.

9. Sistema Moda Italia. Sostenibilità nell'industria Tessile-Abbigliamento-Moda (Sustainability in the Textile-Clothing-Fashion Industry). 2016. Available online: https:/www.sistemamodaitalia.com/it/sos tenibilita (accessed on 24 November 2020).

10. ISPRA-Istituto Superiore per la Protezione e la Ricerca Ambientale. Rapporto Rifiuti Urbani. 2013. Available online: https://www.isprambiente.gov.it/files/pubblicazioni/rapporti/rapporto-rifiuti-urbani-edizione-201 3/Rapporto_rifiuti_urbani_edizione_2013.pdf (accessed on 24 November 2020).

11. Agenda, G.F.; The Boston Consulting Group. Pulse of the Fashion Industry. 2017. Available online: http: //globalfashionagenda.com/wp-content/uploads/2017/05/Pulse-of-the-Fashion-Industry_2017.pdf (accessed on 13 March 2018).

12. Moazzem, S.; Daver, F.; Crossin, E.; Wang, L. Assessing environmental impact of textile supply chain using life cycle assessment methodology. J. Text. Inst. 2018, 109, 1574-1585. [CrossRef]

13. Bhatia, D.; Sharma, A.; Malhotra, U. Recycled fibers: An overview. Int. J. Fiber Text. Res. 2014, 4, 77-82.

14. Rubino, C.; Liuzzi, S.; Stefanizzi, P.; Martellotta, F. Textile wastes in building sector: A review. Model. Meas. Control. B 2018, 87, 172-179. [CrossRef]

15. Carbonaro, C.; Giordano, R.; Montacchini, E.; Muñoz, M.; Tedesco, S. EDILTEX; new building materials from textile wastes. An experience of industrial symbiosis practices. In Proceedings of the 24th International Sustainable Development Research Society Conference Action for a Sustainable World: From Theory to Practice, Messina, Italy, 13-15 June 2018. 
16. Targa, G. TECA panel, Textile Experimental Composite Acoustic. Analysis, Project and Development of Sound Absorbing Panels for the Indoor Environment Based on Textile Waste. Master's Thesis, Collegio di Architettura, Politecnico di Torino, Torino, Italy, 2019.

17. Bruno, L.; Cirillo, M. Not Bed Technology: Mattress Recycling for the Development of an Insulator Added with a Phase Change Material. Master's Thesis, Collegio di Architettura, Politecnico di Torino, Torino, Italy, 2019.

18. ISO-International Organization for Standardization. Environmental Management-Life Cycle AssessmentPrinciples and Framework. 2006. ISO 14040:2006. Available online: http://www.cscses.com/uploads/2016328/2 0160328110518251825.pdf (accessed on 13 December 2020).

19. ISO-International Organization for Standardization. Environmental Management-Life Cycle AssessmentRequirements and Guidelines; International Standard Organization: Geneva, Switzerland, 2018; ISO 14044:2018.

20. Montacchini, E.; Tedesco, S.; Fiorina, S.; Giusto, L. Da scarti tessili a ecoprodotti per l'edilizia: Nuovi scenari di economia circolare. In Proceedings of the International Conference 5R-Refuse, Reduce, Repair, Reuse, Recycle, Rome, Italy, 24 May 2019.

21. Chaduvula, U.; Viswanadham, B.V.S.; Kodikara, J. A study on desiccation cracking behavior of polyester fiber-reinforced expansive clay. Appl. Clay Sci. 2017, 142, 163-172. [CrossRef]

22. Agrawal, S.K.; Watile, R.K.; Mohata, P.V.; Makwana, S.C. Utilization of textile apparel waste in clay brick. Int. J. Adv. Res. Eng. Technol. 2013, 4, 48-52.

23. Gonilho-Pereira, C.; Faria, P.; Fangueiro, R.; Martins, A.; Vinagre, P.; Ratão, S. Performance assessment of waste fiber-reinforced mortar. Mater. Sci. Forum 2013, 730-732, 617-622. [CrossRef]

24. Fantilli, A.P.; Sicardi, S.; Dotti, F. The use of wool as fiber-reinforcement in cement-based mortar. Constr. Build. Mater. 2017, 139, 562-569. [CrossRef]

25. UNI-Ente Nazionale Italiano di Unificazione. Sustainability of Construction Work-Assessment of Environmental Performance of Buildings-Calculation Method; Ente Nazionale Italiano di Unificazione: Milan, Italy, 2011; UNI EN 15978:2011.

26. Giordano, R. I Prodotti Per L'edilizia Sostenibile; Sistemi Editoriali: Napoli, Italy, 2010.

27. Assosistema, Strategia Rifiuti Zero: Un Contributo dal Tessuto Riutilizzabile. Available online: http://www.assosistema.it/wp-content/uploads/2015/04/Relazione-Patrizia-Ferri-USEREUSE-26-m arzo-2015-def.pdf (accessed on 24 November 2020).

28. EDGE. Fashion Industry Waste Statistics. Available online: https://edgexpo.com/fashion-industry-waste-sta tistics/ (accessed on 24 November 2020).

29. World Wear Project, Why Recycle Shoes and Clothing? Available online: http://worldwearproject.com/about -us/global-responsibility (accessed on 24 November 2020).

30. European Commission. Communication: Clean Energy for all Europeans Package, Brussels. 2015. Available online: https:/ec.europa.eu/energy/topics/energy-strategy/clean-energy-all-europeans_en (accessed on 10 December 2020).

31. Ministero Dell'ambiente e dello Sviluppo Economico-Governo Italiano. Piano Nazionale Integrato per l'Energia e il Clima. 2019. Available online: https://www.mise.gov.it/images/stories/documenti/PNIEC_final e_17012020.pdf (accessed on 10 December 2020).

32. PNIEC; Enea-Agenzia Nazionale Per le Nuove Tecnologie, L'energia e lo Sviluppo Economico Sostenibile. Quaderno: L'efficienza Energetica nel Settore Industriale; ENEA: Roma, Italy, 2011.

Publisher's Note: MDPI stays neutral with regard to jurisdictional claims in published maps and institutional affiliations.

(C) 2020 by the authors. Licensee MDPI, Basel, Switzerland. This article is an open access article distributed under the terms and conditions of the Creative Commons Attribution (CC BY) license (http://creativecommons.org/licenses/by/4.0/). 